\title{
Solid Waste Management and Environmental Injustice in Poor Communities in Kinshasa: A Cultural theory and Systems Approach
}

\author{
Nzalalemba Serge Kubanza \\ Global Change Institute, University of the Witwatersrand, Johannesburg, South Africa \\ School of Geography, Archaeology and Environmental Studies \\ Department of Geography and Environmental Studies \\ University of the Witwatersrand, Johannesburg, South Africa \\ Tel: 27-798-182-996 E-mail: sergekubanza1@yahoo.fr \\ Mulala Danny Simatele \\ School of Geography, Archaeology and Environmental Studies \\ University of the Witwatersrand, P/B 1, 2050, Johannesburg, South Africa \\ Tel: 27-833-836-884Ｅ-mail: Mulala.simatele@wits.ac.za
}

Received: November 27, 2018 Accepted: December 21, $2018 \quad$ Published: X, 2019

doi:10.5296/emsd.v8i1.14288ＵRL: https://doi.org/10.5296/emsd.v8i1.14288

\begin{abstract}
This paper discusses injustice in solid waste management (SWM) and its impact on poor communities in Kinshasa, the capital of the Democratic Republic of Congo (DRC). It is argued that poor communities in Kinshasa tend to be the most affected by irregularities in solid waste collection and management. A divide between the rich and poor neighbourhoods is experienced in solid waste management engendering injustice in the city of Kinshasa. Using a qualitative and quantitative research methodology, it is suggested that the current governance systems for SWM in Kinshasa, is unfair by all the different ideas of fairness. In view of this, a cultural theory and systems approach are introduced to determine how actors (fatalist, hierarchist, individualist and egalitarian) influence the management of solid waste and how they are engagement can create environmental justice in SWM in Kinshasa. The paper provides that if the ideal form of urban SWM could be realised in Kinshasa, it should be
\end{abstract}


called participatory resource recovery governance. An environmental policy tailored to very local circumstances-together with some financial support from the government public sector and private companies, and the deployment of social awareness campaigns designed to reduce the generation of "waste" at source (and to emphasise the economic resource value of the misnomer of "wastes")-could succeed in shifting things towards participatory resource recovery governance. In it, all stakeholders would share equitably the responsibility of resource recovery and environmental protection, if not restoration.

Keywords: Environmental justice, Cultural theory, Solid waste management, System analysis, Kinshasa

\section{Introduction}

Solid waste management (SWM) and environmental justice (EJ) have long been studied in the literature (Walker, 2009; Fan, 2006; Hillman, 2006; Pearce, et al., 2006; Chaix, et al., 2006). Increasing attention has been given to the issue of inequalities in the distribution of environmental quality in the city. Social inequalities in the distribution of environmental quality, their causes and consequences, and potential remedies have spread rapidly over the last decade (Patel, 2009; Meyers, 2008). Attempts to formulate policies to lessen environmental injustice have been significant. The rise of EJ discourses as a social issue and its implications in current debates on whether injustice as a factor affecting life outcomes has received considerable attention (Chaix et al., 2006). EJ is used to frame waste-related injustice. This has been evidenced by the Global North's practice of using the Global South as a dumping ground (Thompson, 2008; Pollock and Vittes, 1996).

Observations revealed that poor urban dwellers in many cities of the developing world continue to suffer from environmental injustices while one of the principles of EJ is that public policy must be based on mutual respect and justice for all peoples, and free from any form of discrimination. It requires the right of individuals to participate in national and local development projects as equal partners at all levels of decision-making, including assessment, planning, implementation, enforcement and evaluation (Binns et al., 2012 and Cheru, 2002). These principles, as observed by Binns et al., (2012), and Cheru, (2002) are evident only on paper and political speeches; they are seldom implemented in urban planning and development policy in the context of Sub-Saharan Africa. It is argued that solid waste often ends up in the poorest and least powerful communities in cities of the Democratic Republic of Congo (Kubanza and Simatele, 2017). Poor neighbourhoods in cities of the Democratic Republic of Congo, for example, are often overlooked and ignored by local authorities and, as a result, tend to be the most affected by irregularities in solid waste collection and management. Kihangi, (2012) and Mzidzornu, (2004), for example, note that the current approach to urban development, planning and management, based on central government, tends to place little emphasis on the importance of environmental wellness and its contribution to the health of urban residents. Simatele, (2012), and supported by Massey, (2004), observe that the victims of this policy direction are generally the poor who, in most cases, are geographically located in urban environments that bear a disproportionate share of environmental costs. 
Furthermore, observations reveal that the lack of community participation in SWM activities is the result of a number of factors, the most relevant being the continued implementation of the top-down policy and strategy in the Democratic Republic of Congo (Kihangi, 2012; Dougall and McGahey, 2003). These policies and strategies not only deprive the poor of their right to vote, but also subject them to different vulnerabilities (Kihangi, 2012). A more decentralised community organisation system in this instance would, however, possibly result in the adoption of pro-poor strategies that would shift the locus of power from the elite members of society to the poor. Until the urban poor are allowed to articulate their views and carve their own future, urban processes such as SWM and designing more inclusive development agendas will always elude urban managers.

It is for this reason that, this study uses the cultural theory and systems analysis to determine how actors in the form of four social solidarities (fatalist, hierarchist, individualist and egalitarian) influence the management of solid waste and how they interact dynamically so that those at the bottom of the pyramid of dignified human development may be brought to a level where they care to engage in a debate over such a grand challenge for this century-of cities as forces for good in the environment. Furthermore, the objective of the investigation is to discuss urban EJ and the associated consequences on the urban poor in Kinshasa, the capital of the Democratic Republic of Congo (DRC) from a solid waste and EJ perspective. The paper begins with an introduction and provides the methodology used in the study which introduces the results of the investigation. The paper then discusses the results through the lens of the cultural theory and systems analysis, and concludes with a recommendation.

\section{Research Approach}

This paper is based on information gathered through two research processes. First, the research process includes a comprehensive review of archival records, and peer-reviewed journal articles on EJ in SWM both in a global and local context. Second, the research process includes a qualitative field-based survey conducted in the city of Kinshasa in three distinct locations; Kisenso, Ngaliema and Limete (see Figure 1). The review process of archival records and existing literature involved a search of literature using the library database of different Universities in the Democratic Republic of Congo and in South Africa (i.e. University of Kinshasa, Université Pédagogique Nationale, Université Protestante du Congo, Witwatersrand, Pretoria, Johannesburg, Cape Town, KwaZulu Natal and Stellenbosch). In addition to this, web-based search engines such as google, yahoo and google scholar were employed to search for recent journal articles on the topic. Both library and internet searches yielded an estimated 120 journal articles and 8 text books focusing on EJ and SWM in a global and regional context. A rapid appraisal and meta-analysis of these pieces of literature resulted in the selection of a total number of 40 peer-reviewed articles focusing on environmental issues in the global North and 15 on the global south being selected for inclusion in informing the argument presented in this paper. Other grey literature from the print media: newspaper articles, reports of workshops and press conferences were also engaged with in order to have a comprehensive understanding of local issues about the state of SWM in the city of Kinshasa. 


\section{Macrothink}

Field-based data was collected through methods inspired by the tradition of participatory research. In order to identify the research participants, three (3) population lists for each of the study sites were constructed: Kisenso comprised a total of 200 participants; Ngaliema had 100, while Limete was comprised of 150 research participants. After scrutinising the three population lists, it was purposely decided to interview $30 \%$ of the research participants across the three sites. This process resulted into a sample population of 60 participants drawn from Kisenso, 30 participants from Ngaliema and 45 from Limete. In total, a sample of 135 research participants was drawn from across the three sites. In the processing of selecting the research participants and to ensure that each participant had an equal probability of being selected, the following equation was employed:

$$
\mathbf{K}=\frac{N}{n}=\left\{\frac{\text { size of population }}{\text { size of sample }}\right\}
$$

$\mathbf{K}=$ the interval ratio at which participants were selected.

In view of the above equation, an interval ratio of 3 was used to select the research participants across the three sites. This process entailed that every third participant was selected for inclusion in the study with the first participant being purposively selected. In order to select the households, a random sampling method was applied to every street, then an interval of three houses was applied across the study sites. Every first and third house on each street was selected and surveyed. Moreover, in complexes with several households, at least two households in each complex were randomly selected and a questionnaire was distributed to the heads of the households. Despite these sampling methods, some homeowners refused to participate in the survey and the researcher had to move to the next closest household. In addition, the managers/proprietors of businesses such as shops, supermarkets, restaurants and hotels, were interviewed. In the absence of sample frames, the random sampling technique could not be employed. With the help of the field assistants, businesses and institutions were selected by convenience and those who consented were interviewed. The process went on until the target number of interviews had been conducted. Figure 1 presents the location of the study area. 


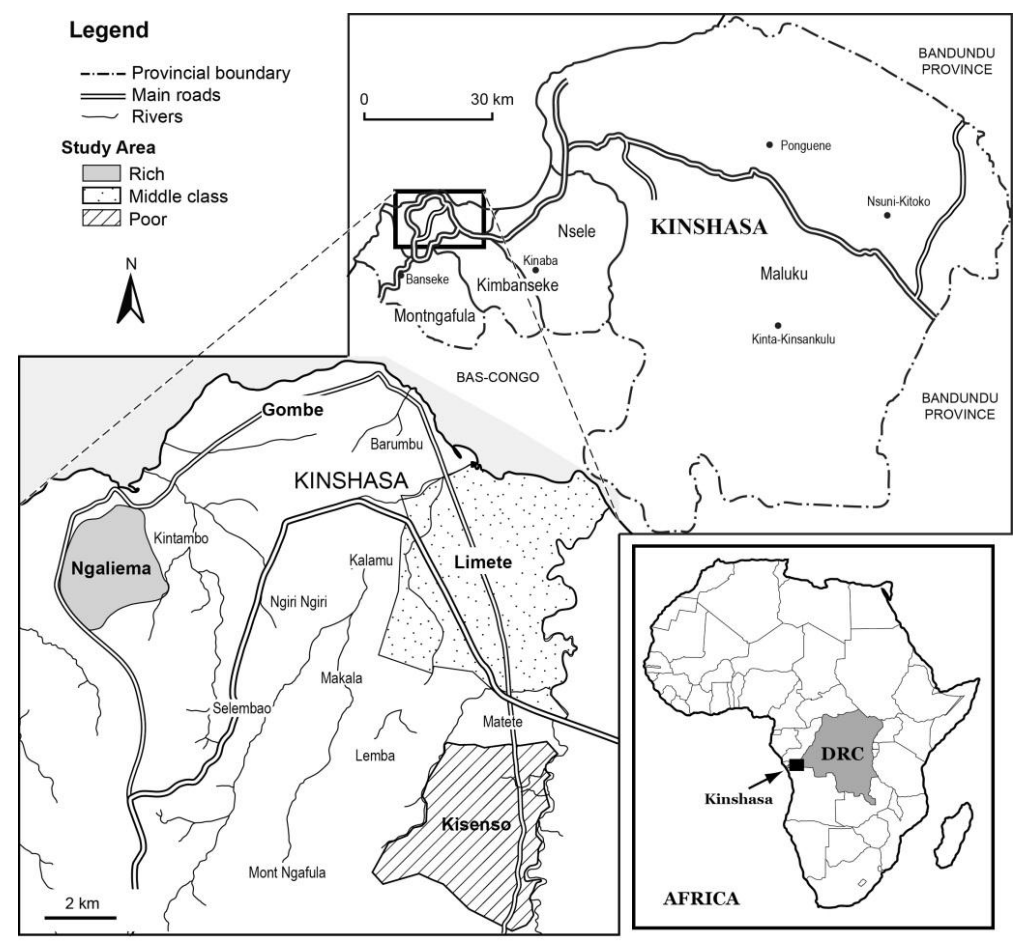

Figure 1. Location of the Study Area. Source: Cartography Unit, (2018), University of the Witwatersrand, School of Geography and Environmental Studies, South Africa

As shown in Figure 1, the study was carried out with the local community members in the selected sites (Ngaliema, Limete and Kisenso). The choice of these sites was justified by the observations that the urban poor in Kinshasa face many complex barriers of access to EJ in SWM and they live in an unhealthy environment compared to those of the wealthy communities. The choice of these three (3) study areas was further justified by the need to assess variations in the quality of SWM services provided to the residents of different socio-economic communities. A total number of 10 institutions were interviewed in Kinshasa and 5 were interviewed in each of the 3 selected municipalities. The 10 officials were drawn from the central and local government institutions in charge of urban governance in Kinshasa using a snowball technique. Semi-structured interviews were the main data collection tool used to collect information from government officials, particularly the urban authorities of the Department of Environmental Affairs/City Governance. Non-Governmental Organisations (NGOs) and other Community-based Organisations (CBOs) whose activities involve SWM were interviewed using the same semi-structured interviews. Generally, the choice of these stakeholders was influenced by their activities and the roles they play in SWM in Kinshasa. Due to the nature of the data collected, there is an element of cross-disciplinary Systems Thinking. The main objective of this study is to address environmental injustice in SWM and, through systems thinking, to develop pragmatic policy interventions to redress it. To do so, we come to the view that theories of environmental injustice (with their origins in the discipline of Sociology, in particular, the sociology of Law) should first be transcribed into the framework of the theory of plural rationalities from 
Anthropology (the theory is sometimes referred to as Cultural Theory). Cultural theory can then be deployed to diagnose the expected low deliberative quality of governance (Ney, 2009) for SWM in Kinshasa and accordingly point to options for elevating deliberative quality, through specific changes to the structure of governance. In other words, this study seeks a prognosis of how to rid Kinshasa of environmental injustice in respect of municipal solid waste.

\section{EJ in SWM in Kinshasa, DRC}

The urban crisis in the Democratic Republic of Congo (DRC) is a classic example of the scars left by the colonial empire and news wounds caused by the failure of the post-colonial state to meet the minimal environmental needs of its citizens (Kihangi, 2012). After more than a century of European colonial exploitation, and fifty six (56) years after independence, the official approach to national development and urban management seems to be disconnected from reality on the ground. Simatele and Emtabokonga, (2015) for example, observe that a number of urban indicators in the Congo reveal the inability of national and local governments to guide sustainable urban development. Urban managers have an intrusive incapacity and indisposition to harness efforts from different social actors towards developing sustainable mechanisms for urban development. A natural consequence of this state of affairs has been the subjection of a large proportion of the urban residents, especially the poor, sinking further into poverty and urban deprivation (Kihangi, 2012; Dougall and McGahey, 2003).

Despite the prevalence of urban poverty and political instability, cities such as Kinshasa have continued to lure people into its parameters, in spite of the fact that the current civil conflict has resulted into weakening institutional frameworks and the destruction of physical infrastructure (Kubanza and Simatele, 2016). Venot and Floriane, (2013), for example, observe that regardless of the unhealthy living conditions in urban areas of the Congo, cities continue to be the favorite destination of many Congolese. This situation is largely due to the fact that urban areas in the Congo, as is the case in many developing countries, are better placed in terms of the provision of socio-economic amenities compared to their rural counterparts (Dougall and McGahey 2003). It must be noted that although urban areas in the Congo are better placed than rural areas, the plight of the urban poor continues to worsen (Venot and Floriane, 2013). High levels of corruption, bureaucratic harassment and the lack of checks and balances have continued to hamper growth and subject the urban poor in Kinshasa to different social deprivation markers and environmental issues. Kihangi, (2012) and Mzidzornu, (2004), for example, note that the current approach to urban development, planning and management, based on central government, tends to place little emphasis on the importance of environmental wellness and its contribution to the health of urban residents. Simatele, (2012), and supported by Massey, (2004), observe that the victims of this policy direction are generally the poor who, in most cases, are geographically located in urban environments that bear a disproportionate share of environmental costs.

Simatele and Emtabakonga, (2015), as well as Kihangi, (2012), for example, are of the view that the misdirection and long term misuse of government resources in the areas of finances, 
delivery of infrastructure services and government regulation have led to the poor performance by municipal institutions in terms of ensuring environmental sustainability and equitable distribution of environmental burden among urban residents in the Congo. Although the reasons for this development may certainly be associated with historical events, contemporary political processes have played a pivotal role in spreading the colonial legacy whose laws, institutions, and structures were totally inappropriate for addressing environmental challenges that are currently faced by the urban poor (Ako et al., 2013). Inequitable distribution of resources has largely facilitated a process where the urban poor neighborhoods look like a lunar landscape, with potholes, plugged drains and mountains of solid waste. In many cases, regular refuse collection has ceased, and basic maintenance of infrastructure in these poor neighborhoods has become a distant memory. The uncollected waste according to Nsokimieno, (2010) has become not only a threat to the health of the poor and less powerful people in the Congo, but it also reveals major environmental injustices (see Kubanza and Simatele, 2018; Rapten, 1998; Medina, 1997). It reveals profound theoretical and practical issues pertaining to the right to good health and the right to urban citizenry. It also reveals the challenges that SWM presents to urban managers as well as the perpetuation of environmental injustice against the poor, an aspect that remains a critical challenge for policy intervention and development (Nsokimieno, 2010; Petts, 2005).

Mangenda et al., (2014), for example, observe that the majority of urban households in Kinshasa tend to store their waste either in open containers, plastic bags, or dug-out dumps at the back of their residential units because of the absence of SWM infrastructure. In the context of Kinshasa, Kubanza and Simatele, (2016) argue that the municipal authorities have had difficulties over the years in providing the most basic services for waste management within their jurisdictions (see also Nsokimieno, 2010; Thompson, 1998). As a result, uncollected waste, often mixed with other wastes such as human and animal pathogens, is generally dumped indiscriminately into streets, drains, and open spaces, thus contributing to blockages of drainage systems and eventual flooding of the city, especially in poor neighborhoods (Mangenda, et al., 2014; Nsokimieno, 2010). Simatele and Etambakonga, (2015) further observe that a large proportion of urban waste in Kinshasa is geographically located in areas where the poor people live. This is because the poor people are powerless and lack the voice loud enough to be heard by the authorities who, in most cases, are from the elite group in society (Achankeng, 2003). Nsokimieno, (2010) and supported by Kubanza and Simatele, (2016) argue that the burden of solid waste in Kinshasa seems to weigh heavily on the poor...this is partly because the poor people are usually invisible or unrepresented in policy making. A discussion with the research participants from all the three sites revealed that the collection of waste by the authorities seems to be a peripheral issue. Research participants argued that waste is rarely collected in their respective locations. Only minimal effort is devoted to solid waste collection in wealthy urban neighbourhoods. Figure 2 illustrates the contrast and inequality encountered in solid waste collection in Kinshasa. 


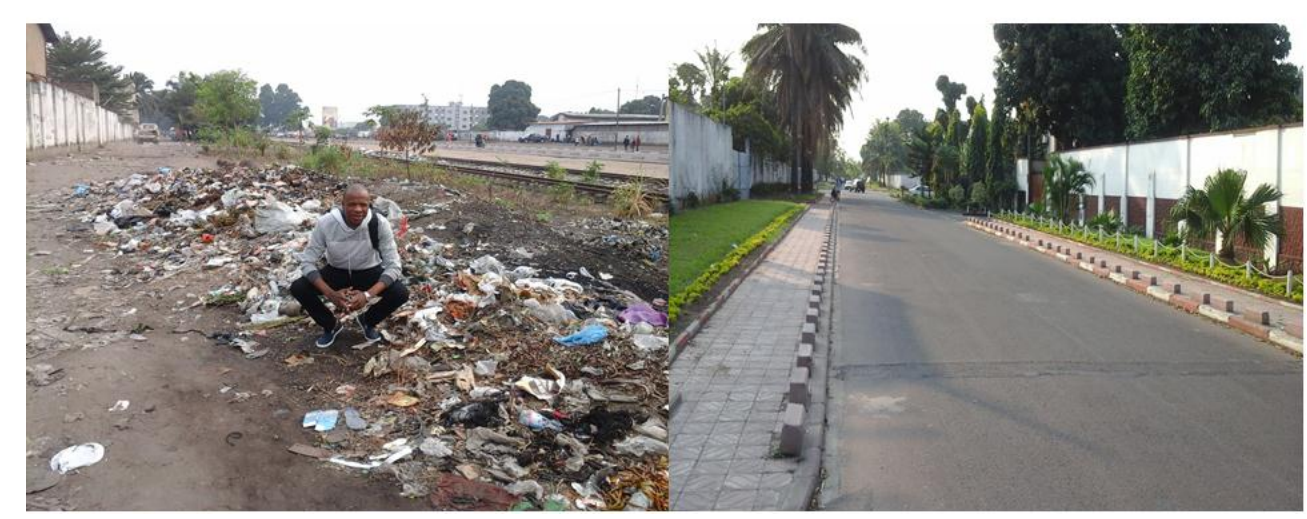

Figure 2. Inequality in SWM and collection in Kinshasa

As shown in Figure 2, solid waste is spread out in the poorest areas of the city. This state of affairs has created a situation in which most of the solid waste generated in Kinshasa is disposed of as landfill in areas available in poor neighbourhoods, despite the fact that most of solid waste is generated in the richest areas. This is the result of a lack of effective interactions and communication between the city council and the municipalities in Kinshasa. Thus, Table 1 illustrates, for example, the perceptions of the research participants on the frequency of solid waste collection by local authorities in Kinshasa.

Table 1. Research participants' perceptions on solid waste collection in the study sites

\begin{tabular}{|l|l|l|}
\hline No. times of solid waste collection & Total No. Citations & \% \\
\hline Never & 20 & 50 \\
\hline Once a month & 10 & 25 \\
\hline Every Fortnight & 5 & 12 \\
\hline Weekly & 3 & 8 \\
\hline Occasionally & 2 & 5 \\
\hline Total & 40 & 100 \\
\hline
\end{tabular}

Source: Field-based materials, 2018.

According to the information in Table 1,50\% of the respondents argued that solid waste is never collected in their suburbs, $25 \%$ of the respondents also argued that waste was collected only once a month, while $5 \%$ of the respondents reported that, their waste is occasionally collected. The overall picture shows that the majority of the population does not have access to SWM services. In view of the above findings, it was important to engage with participants to determine who they considered responsible for solid waste collection and management. These views are shown in Table 2. 
Table 2. Perceptions of research participants on the responsibility of solid waste collection

\begin{tabular}{|l|l|l|}
\hline Who is responsible for SW & No. citations & \% \\
\hline The city council/government & 35 & 47 \\
\hline The community & 21 & 28 \\
\hline Households & 11 & 15 \\
\hline Individuals & 7 & 10 \\
\hline Total & $\mathbf{7 4}$ & $\mathbf{1 0 0}$ \\
\hline
\end{tabular}

Source: Field-based material 2018

Table 2 suggests that $47 \%$ of the research participants reported that Kinshasa City Council was responsible for waste collection while $28 \%$ considered the community as responsible for waste collection and management. What is interesting in Table 2 is that only $10 \%$ of the respondents felt that waste management was an individual responsibility. Thus, the overall picture in Table 2 is indicative of the fact that many participants did not feel responsible but shifted the SWM obligation to the government. However, a senior solid waste manager from Kinshasa's local authority revealed that solid waste collection in Kinshasa has unofficially become a private sector and/or non-governmental responsibility as they carry out most of the collection work and management. He stated:

"We must accept the reality on the ground. Yes on paper, it is our responsibility to collect and manage waste. But the truth is that we have failed for a long time now. We do not have resources and things are going to get worse. Everyone must now accept that solid waste is now the responsibility of NGOs and the private sector. As a government, we will provide an enabling environment for us to work together to develop an effective waste management system" (Pers.com 2018a).

From the above argument, it is obvious that the government and its local agencies are absent in SWM and this state of affairs is an enough reason to worry about issues of justice in SWM in Kinshasa. If the government is absent, a pertinent question to ask is, "who is then responsible for protecting the most vulnerable groups in society from environmental hazards"? The absence of formal institutions essentially entails that the urban poor are at the mercy of the most powerful groups of people that have the power to dispose of waste indiscriminately. A senior urban planner, for example, pointed out that:

"Urban planning and service delivery in Kinshasa have become strongly influenced by the most powerful and wealthy people. The city as it currently stands reflects the needs and aspirations of the elite. As planners, we have tried to include the aspirations of the poor people into urban development and planning policy, but money, and plenty of it, determines whose voice is to be heard and where the services are directed" (Pers.com 2018b).

For example, the failure of municipal authorities to properly manage solid waste and regulate private operators has resulted in a situation in which the poor people have had to pay a lot of money to access solid waste services. Table 3 shows the cost of solid waste billed by private solid waste collectors in the three study sites. 
Table 3. Selected solid waste and cost associated with collection.

\begin{tabular}{|l|l|l|l|}
\hline Type of waste & Weight in kilogram & Cost in Congolese Francs & Cost in US \$ \\
\hline Household waste & $10 \mathrm{~kg}$ & 500 & 0.54 \\
\hline Carton boxes/plastics & $10 \mathrm{~kg}$ & 300 & 0.32 \\
\hline Tins and bottles & $10 \mathrm{~kg}$ & 600 & 0.65 \\
\hline Grass cuttings /shrubs and tree trunks & $10 \mathrm{~kg}$ & 1000 & 1.1 \\
\hline
\end{tabular}

Figures obtained from the research participants during interviews.

Source: Fieldwork based materials 2018.

Although the cost of solid waste by private actors may seem affordable (see Table 3) when examined in a global context, the cost is quite significant when scrutinised an economy where the majority of people live on less than a dollar and twenty-five cents $(\$ 1.25)$ per day (see Simatele and Etambakonga, 2015). In view of this, we can argue that the cost of US 54 cents for a $10 \mathrm{~kg}$ bag of household waste may have significant implications on the ability of poor households to obtain other essential services that they may require (e.g. food, health and education). Mangenda et al., (2014) argue that the lack of SWM facilities and sometimes the associated cost have contributed significantly to the increase in waste dumping in Kinshasa. A female respondent aged between 35 and 40 years from Limete stated:

"I am one of the culprits responsible for dumping waste in my neighbourhood. I do not like doing it but what choice do I have? The council does not come to collect the waste. Then you have private companies whose waste collection costs are not cheap. So I end up dumping. This is the cheapest option for me" (Pers.com 2018c).

In-depth discussions with various research participants, particularly in Kisenso and Limete, revealed that the majority of Kinshasa residents are unable to pay for solid waste collection services. Table 5, for example, reflects this state of affairs.

Table 4. Ability of the research participants to pay for solid waste collection by location

\begin{tabular}{|l|l|l|l|l|l|l|}
\hline \multirow{2}{*}{ Nature of response } & \multicolumn{6}{|c|}{ Study Locations } \\
\cline { 2 - 8 } & \multicolumn{2}{|c|}{ Kisenso } & \multicolumn{2}{c|}{ Ngaliema } & \multicolumn{2}{c|}{ Limete } \\
\hline & Number & $\%$ & Number & $\%$ & Number & $\%$ \\
\hline Yes I can afford to pay & 10 & 17 & 42 & 93 & 5 & 17 \\
\hline No I can't afford to pay & 45 & 75 & 3 & 7 & 18 & 60 \\
\hline I am not sure if I can pay & 5 & 8 & 0 & 0 & 7 & 23 \\
\hline Total number of participants & 60 & 100 & 45 & 100 & 30 & 100 \\
\hline
\end{tabular}

Source: Field-based materials, 2018

It is suggested in Table 4 that $75 \%$ and $60 \%$ of the research participants in Kisenso and Limete, respectively are unable to pay for solid waste collection, whereas almost $93 \%$ of the respondents in Ngaliema have declared to be able to pay. What is interesting about the information in Table 4 is that both Kisenso and Limete are low income areas, while Ngaliema is a high income residential area. A resident of Ngaliema aged between 35-40 years commented: 
"As there is almost no formal SWM system in our neighbourhood, as residents of Ngaliema, we decided to use private services for the collection of our waste. We pay for this service every week. This is why you notice that our neighbourhood is cleaner compared to other districts in the city. We also have the privilege of staying with some government authorities and other executives from the private sector in our neighbourhood. Their presence in this neighbourhood plays a major role in the management of waste in our environment. Because of their presence, the municipal authorities try to keep the area clean, something that does not happen elsewhere. So we take advantage of their presence", (Pers.com 2018d).

The overall picture presented in Table 5 shows that SWM is a major challenge for the poor in Kinshasa as they have neither the resources nor access to the infrastructure to efficiently dispose of their waste in order to address the likely of waterborne or vector diseases. Due to the inability to effectively manage their waste, or to have waste removed by the local authority or private actors, research participants were asked to identify and rank some of the challenges associated with uncollected waste and these are represented in Table 5.

Table 5. Environmental challenges associated with solid waste in the three research sites

\begin{tabular}{|l|l|l|l|}
\hline Nature of Responses & No. respondents & $\%$ & Rank * \\
\hline Increased case of diseases such as typhoid fever, cholera and malaria & 54 & 49 & 1 \\
\hline Bad smells (air pollution) & 26 & 24 & 3 \\
\hline Danger to children & 17 & 15 & 2 \\
\hline Water contamination & 8 & 7 & 3 \\
\hline Destruction of vegetation & 5 & 5 & 3 \\
\hline Total & $\mathbf{1 1 0}$ & $\mathbf{1 0 0}$ & - \\
\hline
\end{tabular}

NB: * the smaller the number, the most important factor

Source: Field-based material, 2018

From the information in Table 5, it is evident that the research participants were of the view that uncollected waste had health implications and was a danger to the children represented at $49 \%$ and $15 \%$ and ranked 1 and 2 respectively. Although air pollution is represented at 24\%, it is ranked third, as is the case for water contamination and vegetation destruction. These views are similar to the findings suggested in the work of Mangenda, et al. (2014); Din and Cohen (2013) and Achankeng (2003). A resident of Kisenso aged between 30-35 years commented:

"As a resident of Kisenso, I say that we are completely forsaken by the authorities. It seems that environmental services responsible for waste collection do not exist in the city. We live in garbage and suffer from the smells and pollution resulting from poor SWM. We do not have a solid waste collection service in our area. There are open dumpsites and illegal landfills in our neighbourhood and every day, we suffer from infectious diseases, including typhoid fever and malaria, etc." (Pers.com, 2018e).

The overall picture presented in this section suggests that solid waste in Kinshasa has become one of the challenges of urban development. Policy development and waste management 
strategies for the city of Kinshasa seem to be out of touch with the reality on the ground. As a consequence, the urban poor have been subjected to live in conditions where solid waste and other forms of waste have become part of the landscape and a norm.

\subsection{EJ, SWM and Governance: a Cultural Theory and Systems Approach}

The results presented in this study show that Kinshasa has a conventional infrastructure inherited from the past, particularly, one that provides the SWM services. The problem, however, is that the service extends to just a privileged minority in the city. There is environmental injustice, as some observers have called it (Dodds and Hopwood, 2006; Walker, 2009; Leonard and Pelling, 2010). One can argue whether cultural theory could generate new and different ideas about environmental injustice when it is transcribed into its native discipline (the sociology of law). The cultural theory framework is observed to be particularly suited to the analysis of environmental injustice and SWM because it offers an approach for understanding and resolving the conflicts and disputes that characterise social and environmental policy. Its four forms of social solidarity (or "ways of organizing") are there set out by way of the four kinds of goods that have long been familiar to economists and political scientists: public, private, common-pool, and club. The idea-and it also holds for solid wastes is that, while the inherent physical properties of the objects are not irrelevant, category membership is under-determined by those physical properties. Solid wastes, of course, are usually seen as "bads", not "goods", except in those circumstances where some actors- they are disparagingly referred to as "scavengers" or worse- regard them as mis-categorised "valuable resources". Beck et al., (2018) argue that, in Cairo, for instance, solid waste/valuable resource management is almost completely in the hands of the Zabbadin, Coptic Christians, for the most part, who make a good living by collecting and skillfully sorting out the household and business refuse, with the edible portion then being fed to their pigs: unclean animals in the eyes of those citizens (the majority) who are of the Muslim faith (Beck et al., 2018). This "malleability" creates some difficulties for those who frame things in terms of environmental injustice, in that the Zabbadin are simultaneously treated as a despised minority- irrefutably unjust-while being quite well rewarded, economically, for their socially valuable contribution, which is admirably just from the individualist perspective. Environmental injustice, cultural theory suggests, will always be a contested concept (as is sustainability; Thompson, 2011; Beck, 2011), because each of the four forms of solidarity has its own idea of fairness, with none of them being reducible to any of the others (see Davy, 1997; Thompson 1998). These ideas of fairness are as follows:

- The individualist voice is pro-market (and pro-private goods). A fair outcome, its proponents are convinced, is one in which those who put most in get most out, and they see a "level playing field" as a crucial pre-condition for that. Equality of opportunity is therefore the individualist idea of fair process, with outcome fairness being the matching of reward to contribution.

- The hierarchist voice is pro-control (and pro-public goods) and is much concerned with order and status: who has the right to do what and to whom. Distribution should thus be by rank and station, and this idea of fairness then requires that, if that orderly 


\section{MInstitute Macrothink}

distribution is not happening, the hierarchy should step in so as to ensure that each gets the desserts appropriate to his or her position within the layered totality.

- Both the individualist and the hierarchical ideas of fairness are anathema to those who speak with the egalitarian voice. Egalitarian actors are levellers (and therefore in favour of common-pool goods). Absolute parity-before, during, and after- is their idea of what is fair. People, they insist, should start off equal and end up equal.

- Those who cannot come up with the entry costs for the market, find themselves categorised as deviants/undeserving poor by the hierarchy, and lack the cohesion and commitment that would enable them to rise up against all sources of inequality, constitute the fatalized and largely voiceless margin. As the discards from all and sundry rain down on them they cope as best they can. "Not in this world" is the fatalist verdict on fairness.

The proponents of environmental injustice, as we see now, are largely egalitarian persuasion: outrageously highlighting the gross unfairness that is being visited upon the fatalised margins in order to castigate the unresponsive and exploitative hierarchies and markets. This, of course, is a perfectly valid and legitimate voice- a voice, moreover, that all too often finds itself ignored and sometimes persecuted- but, as well as needing to be heard, cultural theorists argue, it also needs to be constructively engaged with the other voices. Only then will we be in an institutional position to move towards what are called "clumsy solutions". Kinshasa, at present, is rather a long way from that position. The country's elite-politicians, musicians, businessmen and so on- have turned the capital city into a club good. These elites, in encompassing both status and economic "clout"- the bureaucracy and the bourgeoisie- has excluded the egalitarian voice, while also failing to look after the "lowerarchs" or to level the playing field. In consequence, none of the ideas of fairness are being delivered, and much of the waste that is generated in the wealthier districts ends up being dumped in the poor suburbs, hence their environmental degradation.

In view of the above analysis, it can be argued that there exist clear causal feedback relations among the various factors that contribute to the current plight of SWM in Kinshasa. The Causal Loop Diagram Analysis (CLDA), is a tool for systems analysis, and it illustrates the complex relationships in an observable social, economic or environmental event. CLDA analysis is beneficial in understanding and communicating complex systems involving variables of both qualitative and quantitative measurement (Maxwell 2004a). In the context of this paper, CLDA enabled the researchers to gasp and organise the multifarious causal aspects of SWM in Kinshasa. Causal relationships between variables as shown in Figure 3, were visualised by mono-directional arrows connecting the variables.

The (+, plus) sign at the head of the arrow indicates that the preceding variable is having an "increasing" positive effect on the variable to which the arrows is connected. The (-, minus) sign on the contrary indicates that the preceding variable is having a "decreasing" effect on the variable to which the arrows is connected. Two or more arrows connecting two or more variables create a loop which has either a reinforcing $(\mathrm{R})$ or balancing $(\mathrm{B})$ effect on a given variable within the loop. In the middle of the loop, $(\mathrm{R})$ indicates that the variables are 
reinforcing each other over time and (B) indicates that the variables are balancing each other over time (Haraldsson 2004, Kirkwood 1998).

In addition to the universal CLDA notations, the researchers developed other cyphers to better fit the contextual realities revealed in the three sites included in the study. Coded coloration of mono-directional causal arrows was used to clearly separate and identify different forms of causal relationships within the complex system of solid waste in Kinshasa. Figure 3 shows the current state of SWM and stakeholders' engagement necessary to improve SWM in the city of Kinshasa as well as contribute towards improving environmental justice in a plurality governance approach. The city's large population, the de facto segregation of the homes of the rich and poor into geographically separated areas, and the city's growing economy generate a high volume of solid waste- and lead to the environmental injustice already described. Further analysis suggests that, if three of the four social solidarities, i.e., the municipal authorities (hierarchists), private companies (individualists), along with the NGOs, CBOs, and other community and social organisations (egalitarians), could only but engage with each other, the "management" (or rather "non-management") in SWM could be made a more equitable and productive matter of participatory governance (see Figure 3 below).

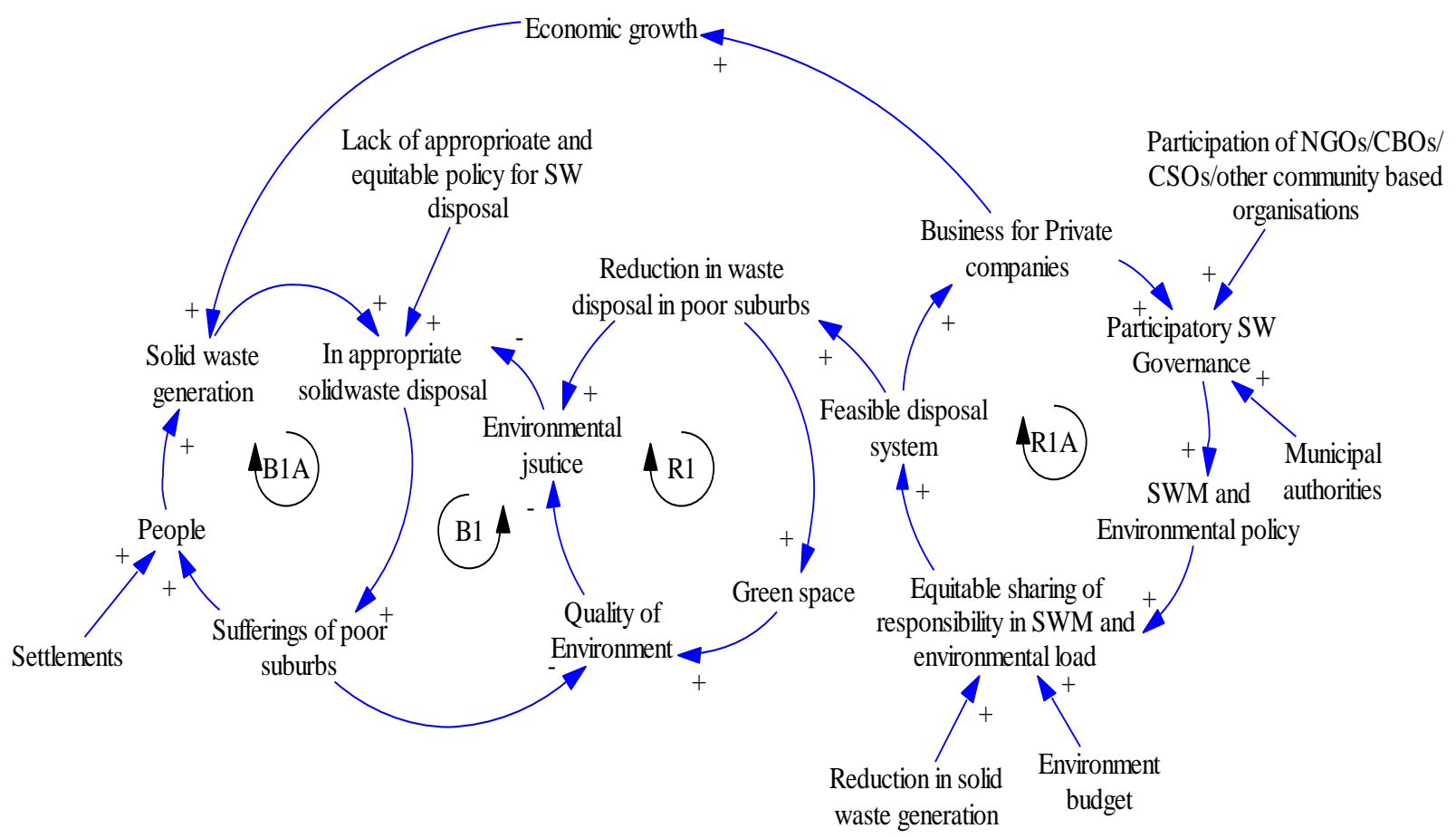

Figure 3. Causal feedback mechanisms showing the current status of SWM and EJ in Kinshasa and attainment of EJ in SWM by participatory governance approach

Figure 3 presents the conceptual causal feedback relations among the variables influencing SWM system in the city of Kinshasa. The causal feedback relations are examined in the form of two types of loops, i.e., reinforcing or positively influencing loops (R), and balancing or disruptive loops or negatively influencing loops (B). Further, Figure 3 presents the 
interlinkage and causal feedback relationships among the various socio-economic, environmental governance variables influencing SWM, and the influence of the three important social solidarities in the city. It is seen that there are clear causal feedback relations among the variables, which contribute to the current plight of SWM, such as, the enormous population, functions in different settlements and economic growth generate high volume of solid waste in the city. However, inappropriate solid waste disposal system on account of lack of appropriate and equitable disposal system leads to dumping of the generated solid wastes in the poor suburbs through a balancing or disruptive feedback loop B1 A. As a result, the quality of environment in the poor suburbs is degraded, which creates environmental injustice in the city through the balancing feedback loop B1. Thus, it is apparent that the mechanism being in operation by feedback loop B1A strengthens the feedback loops B1, and consequently creates environmental injustice in the city with regards to SWM. It is envisaged from Figure 3 that a participatory approach of governance in collaboration with the three influential solidarities of the society would bring about EJ in SWM in Kinshasa.

\section{Summary}

As noted above, the current governance systems for SWM in Kinshasa, is unfair by all the different ideas of fairness (in cultural theory). However, in regimes that are not democratic, the gaining of access by the excluded voices is seldom straightforward. If the ideal form of urban SWM could be realised in Kinshasa, it should be called participatory resource recovery governance. An environmental policy tailored to very local circumstances-together with some financial support from the government public sector and private companies, and the deployment of social awareness campaigns designed to reduce the generation of "waste" at source (and to emphasise the economic resource value of the misnomer of "wastes")-could succeed in shifting things towards participatory resource recovery governance. In it, all stakeholders would share equitably the responsibility of resource recovery and environmental protection, if not restoration. The participatory resource recovery governance should reduce the volume of "waste" to be "disposed of" in the poor suburbs and stimulate business opportunities. Indeed, if there were reductions in waste generation in the poor suburbs, space could be liberated afresh for a re-greening and opening out of their local environments. In short, participatory resource recovery governance promises less environmental injustice in Kinshasa.

\section{Acknowledgements}

Research for this article was supported in part by the Global Change Institute and the life in the city-Wits School of governance. The opinions expressed herein are the authors' own and do not necessarily express the views of the Global Change Institute and the life in the city-Wits School of governance.

\section{References}

Achankeng, E. (2003). Globalization, Urbanization and Municipal Solid Waste Management in Africa. African Studies Association of Australasia and the Pacific, Conference Proceedings - African on a Global Stage, Melbourne, Australia. 


\section{$\triangle$ Macrothink}

Ako, M., Anyidoho, N., \& Crawford, G. (2013). Non-Governmental Organisations, Rights-based Approaches and the Potential for Progressive Development in Local Contexts: Constraints and Challenges in Ghana. Journal of Human Rights Practice, 5(1), 46-74. https://doi.org/10.1093/jhuman/hus031

Beck, B. M., Das, D. K., Thompson, M., Chirisa, I., Eromobor, S., Kubanza, N. S., Rewal, T., \& Burger, E. (2018). Cities as Forces for Good in the Environment: A Systems Approach, in: Mensah,P., Katerere, D., Hachigota, S. and Roodt, A. (Eds), Systems Analysis Approach for complex Global challenges. Springer, Cham, Switzerland.

https://doi.org/10.1007/978-3-319-71486-8_2

Beck, M. B. (2011). Cities as Forces for Good in the Environment: Sustainability in the Water Sector. Warnell School of Forestry and Natural Resources, University of Georgia, Athens, Georgia. [Online] Available: http://cfgnet.org/archives/587

Binns, T., Dixon, A., \& Nel, E. (2012). Africa: Diversity and Development. 1st ed. London: Routledge. https://doi.org/10.4324/9780203153499

Chaix, B. (2006). Children's exposure to nitrogen dioxide in Sweden: investigating environmental justice in an egalitarian country. Journal of Epidemiology and Community Health, 60, 234-241. https://doi.org/10.1136/jech.2005.038190

Cheru, F. (2002). The urban-rural interface: managing fast-growing cities in Africa in F. Cheru (Eds.), African Renaissance: Roadmaps to the challenge of globalization (pp. 153-192). Zed Books, London.

Davy, B. (1997). Essential Injustice: When Legal Institutions Cannot Resolve Environmental and Land Disputes, Springer, Vienna. https://doi.org/10.1007/978-3-7091-6515-7

Din, G., \& Cohen, E. (2013). Modeling Municipal Solid Waste Management in Africa: Case Study of Matadi, the Democratic Republic of Congo. JEP, 04(05), 435-445.

https://doi.org/10.4236/jep.2013.45052

Dodds, L., \& Hopwood, B. (2006). BAN waste, environmental justice and citizen participation in policy setting. Local Environment, 11(3), 269-286.

https://doi.org/10.1080/13549830600558762

Dougall, J. M., \& MeGahey, C. (2003). Urban Environmental Health Strategies, three Community-Based Environmental Sanitation and Hygiene Projects Conducted in the DR-Congo. [Online] Available:

https://www.ircwash.org/sites/default/files/MacDougall-2003-Urban.pdf

Fan, M. F. (2006). Environmental justice and nuclear waste conflicts in Taiwan. Environmental Politics, 15(3), 417-434. https://doi.org/10.1080/09644010600627683

Haraldsson, H. V. (2004). Introduction the Systems Thinking and Causal Loop Diagrams. Reports in Ecology and Environmental Engineering: Report 1, February. Lund, Sweden: Department of Chemical Engineering, Sweden. 
Hillman, M. (2006). Situated justice in environmental decision-making: Lessons from river management in Southeastern Australia. Geoforum, 37(5), 695-707.

https://doi.org/10.1016/j.geoforum.2005.11.009

Kihangi, B. K. (2012). The Environmental Law Framework of the Democratic Republic of Congo and the Balancing of Interests. In Faure, $\mathrm{M}$ and Plessis (Eds.), The Balancing of Interests in Environmental Law in Africa (pp. 95-96). Pretoria university law press, South Africa.

Kirkwood, C. W. (1998). System Dynamics Methods: A Quick Introduction. College of Business, Arizona State University, USA.

Kubanza, N. S., \& Simatele, D. (2016). Social and Environmental Injustices in Solid Waste Management in Sub-Saharan Africa: A Study of Kinshasa, the Democratic Republic of Congo. Local Environment, 21(7), 866-882. https://doi.org/10.1080/13549839.2015.1038985

Kubanza, N. S., \& Simatele, D. (2017). Sustainable Solid Waste Management in Sub-Saharan African cities: Application of System Thinking and System Dynamic as Methodological Imperatives in Kinshasa, the Democratic Republic of Congo. Local Environment.

Kubanza, N. S., Das, D. K., \& Simatele, D. (2017). Some Happy, Others Sad: Exploring Environmental Justice in Solid Waste Management in Kinshasa, The Democratic Republic of Congo. Local Environment, 22(5), 595-620. https://doi.org/10.1080/13549839.2016.1242120

Leonard, L., \& Pelling, M. (2010). Mobilisation and protest: environmental justice in Durban, South Africa. Local Environment, 15(2), 137-151.

https://doi.org/10.1080/13549830903527654

Mangenda, H. H., Nedeff, V., Kunyima, K., Barsan, N., Mosnegutu, E., \& Tomozei, C. (2014). Municipal Waste Management in Limete, Mont Amba District of Kinshasa, Democratic Republic of the Congo. Journal of Engineering Studies and Research, 20(2), 22-55.

Maxwell, J. A. (2004a). Using Qualitative Methods for Causal Explanation. Field Methods, 16(3), 243-264. https://doi.org/10.1177/1525822X04266831

Medina, M. (1997). Informal Recycling and Collection of Solid Waste in Developing Countries: Issues and Opportunities (Working paper \# 24). New York: the United Nations University. [Online] Available: www.gdrc.org/uem/waste/swm-ias.pdf

Messey, R. (2004). Environmental Justice: Income, Race and Health. Global Development and Environment Institute, Tufts University Medford, MA 02155. [Online] Available: http://ase.tufts.edu/gdae

Myers, G. A. (2008). Sustainable Development and Environmental Justice in African Cities. Department of Geography, University of Kansas, Journal Compilation, Blackwell Publishing, Geography Compass, pp. 695-708. https://doi.org/10.1111/j.1749-8198.2008.00111.x

Mzidzornu, M. (2004). Environment protection in Africa: Panorama of the law and practice. 
Journal of Energy and Resources Law, 22, 152-153.

Nsokimieno, M. M. E. (2010). Sustainable Urbanization's Challenge in Democratic Republic of Congo, Institute of Earth Exploration and Information Technology. Journal of Sustainable Development, 3(2), 10-20.

Patel, Z. (2009). Environmental justice in South Africa: tools and trade-offs. Social Dynamics: A journal of African studies, 35(1), 94-110. https://doi.org/10.1080/02533950802666956

Pearce, J., Kingham, S., \& Zawar-Reza, P. (2006). Every breath you take? Environmental justice and air pollution in Christchurch, New Zealand. Environment and Planning A., 38, 919-938. https://doi.org/10.1068/a37446

Pers.com. (2018a). Personal communication with a research participant from solid waste management department, $16^{\text {th }}-29$ th June, 2018. Kinshasa, DRC.

Pers.com. (2018b). Personal communication with a research participant from Town Planning department in the three research sites, $16^{\text {th }}$-29th June, 2018. Kinshasa, DRC.

Pers.com. (2018c). Personal communication with a female respondent aged between 35 and 40 years from Limete, $16^{\text {th }}-29$ th June, 2018. Kinshasa, DRC.

Petts, J. (2005). Enhancing environmental equity through decision-making: Learning from waste management. Local Environment, 10(4), 397-409.

https://doi.org/10.1080/13549830500160933

Pollock, E., \& Vittes, P. (1996). Poverty, Pollution, and Solid and Hazardous Waste: The Linkages for Different Sources. Florida Centre for Solid and Hazardous Waste Management, University of Central Florida, Report \# 96-3, USA.

Rapten, K. (1998). Community Participation in Municipal Solid Waste Management in Developing Countries: The Role of the Informal Sector. New Haven: Yale School of Forestry and Environmental Studies. USA.

Simatele, D., \& Etambakonga, C. L. (2015). Scavenging For Solid Waste In Kinshasa: A Livelihood Strategy For The Urban Poor In The Democratic Republic Of Congo. Habitat International, 49, 266-274. https://doi.org/10.1016/j.habitatint.2015.05.029

Simatele, D. M. (2012). Asset Adaptation and Urban food security in a Changing Climate, a Study of Kalingalinga and Linda Compounds in Lusaka, Zambia. Climate Change, Assets and Food Security in Southern African Cities, Earthscan. 110-13.

Thompson, M. (1998). Waste and Fairness. Social Research, 65(1), 55-73.

Thompson, M. (2011). Sustainability is an Essentially Contested Concept, Surveys And Perspectives Integrating ENvironment \& Society. [Online] Available:

http://sapiens.revues.org/1177

Venot, J. P., \& Floriane, C. (2013). Justice in Development? An Analysis of Water Interventions in the Rural South. Natural Resources Forum 37, United Nation. pp. 19-30. 


\section{Macrothink

https://doi.org/10.1111/1477-8947.12002

Walker, G. (2009). Beyond Distribution and Proximity: Exploring the Multiple Spatialities of Environmental Justice. Antipode, 41(4), 614-636.

https://doi.org/10.1111/j.1467-8330.2009.00691.x

\section{Copyright Disclaimer}

Copyright for this article is retained by the author(s), with first publication rights granted to the journal.

This is an open-access article distributed under the terms and conditions of the Creative Commons Attribution license (http://creativecommons.org/licenses/by/3.0/). 